\title{
Ureter Compression
}

National Cancer Institute

\section{Source}

National Cancer Institute. Ureter Compression. NCI Thesaurus. Code C114479.

Narrowing of the luminal diameter of one or both ureters due to extrinsic pressure. 